\title{
A REPRESENTAÇÃO DA INFÂNCIA NOS POEMAS \\ DE SÓ DE BRINCADEIRA, DE LEO CUNHA
}

Fabiano Tadeu Grazioli*

RESUMO: A poesia de recepção infantil revela um universo de sensações e percepções da parte de quem a produz que implica na maneira de representar elementos irmanados à infância, sejam eles subjetivos ou de cunho confessional, sejam da ordem dos rituais que envolvem a criança e o mundo que ela projeta a partir de suas ações, como os brinquedos e as brincadeiras. O aproveitamento de tais temas na elaboração de poemas para a infância, e a sua exploração faz parte do projeto de construção da obra Só de brincadeira, de Leo Cunha (Positivo, 2018). O artigo separa os poemas do livro em poemas sobre brinquedos e poemas sobre brincadeiras e apresenta análises que procuram perceber a maneira de o autor representar a infância, tomando como ponto de partida o aproveitamento poético do objeto (o brinquedo) ou do jogo/atividade (a brincadeira). Além disso, as análises investem na observação da construção poética de Leo Cunha, observando recursos do gênero lírico que o autor mobiliza nos poemas. Levada à cabo nossa proposta, concluímos que muitas vezes o poema que tematiza um brinquedo, coloca o objeto em atividade lúdica, o que revela a brincadeira que dele emerge e que Leo Cunha, observador e criador, não deixa de aproveitar enquanto recurso poético, além, obviamente, de percebermos latente na sua escrita, o manejo adequado com a linguagem poética e seus meandros.

PALAVRAS-CHAVE: Poesia para a infância; Brinquedos; Brincadeiras.

\section{Introdução}

A infância tem o poder de marcar a subjetividade do adulto artista ao ponto de muitos escritores, na vida adulta, basearem a sua produção literária nas memórias desse período. Em tal contexto, brinquedos e brincadeiras aparecem como uma possível tentativa de representação de elementos da infância dos autores. O último ponto é o caso da obra Só de brincadeira, do poeta mineiro Leo Cunha, com ilustrações de Anna Cunha, contudo, o ponto anterior não serve para descrever sua produção literária, pois ele apresenta, no conjunto de suas obras, uma vasta galeria de temas e motivos para a produção poética, de

\footnotetext{
* Doutor em Letras pelo Programa de Pós-Graduação em Letras da Universidade de Passo Fundo (UPF). Professor da Universidade Regional Integrada do Alto Uruguai e das Missões (URI), Campus de Erechim/RS e da Faculdade Anglicana de Erechim/RS (FAE).
} 
modo que a infância é um dos muitos temas, sendo a grande maioria deles fruto de sua mente inventiva e criativa. Não que os poemas sobre memórias de infância deixem de exigir labor com a palavra; o que queremos esclarecer é que uma pequena parte da produção literária de Leo Cunha concentra-se naquilo que poderíamos considerar as suas memórias de infância, o restante são invencionices do autor. Por outro lado, já ouvimos pesquisadores afirmarem que, mesmo quando o autor não está trabalhando diretamente com suas memórias, sua obra está compondo um painel que é uma tentativa de reajustar, reorganizar, reenquadrar, conscientemente ou não, elementos de seu passado, de sua infância.

A partir de um breve referencial teórico que procura principalmente trazer ao estudo algumas questões relacionadas à representação na literatura, o presente trabalho analisa alguns poemas do conjunto de 25 que compõem a coletânea Só de brincadeira, de autoria de Leo Cunha. Nossa intenção é perceber como os brinquedos e as brincadeiras, nos poemas, transfiguram-se em representações da infância do eu lírico, por isso dividimos a análise em duas seções, "os brinquedos" e "as brincadeiras", nas quais analisamos poemas que se encaixam nesses temas, uma vez que, como demonstraremos, existem diferenças entre o significado desses dois termos nos estudos da infância. Também observaremos elementos que compõem os poemas, tendo em vista as particularidades do gênero lírico e a poesia pensada para o público infantil.

Só de brincadeira é um livro ilustrado que nasceu do encontro dos poemas de Leo Cunha e das ilustrações de Anna Cunha, que realizou o projeto ilustrativo numa viagem pelo continente africano. A capa e o projeto gráfico são de Raquel Matsushita e a diagramação de Cecília Cangello. Texto, ilustração e projeto gráfico estão alinhados de certa maneira que, tais aspectos mereceriam um estudo extenso e aprofundado, que não terá espaço neste trabalho. Aqui buscamos somente estudar alguns poemas da obra, deixando para outra ocasião a empreitada antes anunciada. 


\title{
Breves palavras que dão suporte teórico às reflexões
}

Sobre a necessidade e a capacidade de o ser humano criar representação por meio da palavra, Adilce Manuela Moreno Freire (2010, p. 11), afirma:

\begin{abstract}
A mensagem literária é dirigida para o homem que vive numa época de especialização, isto é, transmite ao homem o conhecimento de uma certa realidade. Através da literatura o homem é capaz de representar as respostas de muitas interrogações que lhes são suscitadas. É de salientar que, de todas as formas de arte, a literatura pode ser considerada como a mais próxima da vida, porque ela como qualquer obra de arte é um produto de teias e efeitos comunicativos, caminhos que se abrem para a configuração de um real sentido e estimulado pela experiência.
\end{abstract}

As dúvidas, as angústias e anseios do ser humano podem ser representadas por meio da palavra literária, que tem a força de fazer emergir, pela escrita ou pela oralidade, as experiências do escritor, que se vê estimulado pelo real sentido que as palavras podem ganhar, já que, segundo Moreno Freire, a literatura é a forma de arte mais próxima da vida. No caso de Leo Cunha, deduzimos que sua relação com os brinquedos e brincadeiras - que aqui representam uma infância que pode ser a sua - são a experiência de que fala a pesquisadora, capaz de ser recuperada e potencializada na literatura. Emanuel Guerreiro, no ensaio $O$ conceito de representação: literatura, religião, cinema, apresenta reflexões que podem ser úteis aos propósitos desta escrita:

A representação é uma forma de compreender, de perceber o mundo, simbólica e referencialmente, mediada por um sujeito; inclui aspectos e elementos reconhecíveis do "universo real", imagem de algo ausente, representado interiormente pela imaginação, configurando-o [...]. Não se trata de uma cópia servil, mas de uma interpretação, de uma leitura pessoal da realidade. É a capacidade de idealizar, aliada à ficção e à transposição, que apresenta metaforicamente a correspondência entre uma pessoa ou objecto e o seu representante. (GUERREIRO, 2010, p. 44)

Importante notar que, segundo o pesquisador, a representação é um recurso que leva o sujeito a perceber o mundo de duas maneira distintas: simbolicamente, ou seja, pelo 
entendimento do uso da linguagem conotativa, simbólica, artística; e referencialmente, fazendo uso de um olhar mais objetivo em relação à realidade representada. Essas experiências não se excluem e estão previstas na percepção das criações artísticas, em especial daquelas que usam da representação para se constituir em artefato artístico. O pesquisador esclarece que a representação não deve ser um retrato fiel da realidade, e sim uma interpretação, um olhar particular para ela.

Em se tratando da representação da cultura popular em Só de brincadeira, os brinquedos e as brincadeiras tornam-se elementos representativos dessa manifestação, sobre a qual Maria Ignez Novais Ayala (2003, p. 106-107) afirma:

Quando se estuda a cultura popular ou a literatura popular (oral ou escrita), a meu ver, se nos preocuparmos apenas com os objetos culturais (textos literários, adereços, instrumentos, objetos utilitários, por exemplo), deixando em segundo plano as pessoas, seus modos de vida e o sentido que tem para elas o universo cultural do qual participam, poderemos deixar de perceber os contrastes, as relações, as diferentes temporalidades que mantêm essa cultura viva e presente. Afinal, é sempre um fazer dentro da vida, como o trabalho, a festa.

A autora chama a atenção para que não se perca o contato com o contexto (pessoas e universo cultural) a partir do qual os produtos culturais que o pesquisador vier a analisar foram concebidos. No caso da poesia de Leo Cunha, não temos essa necessidade de ouvilo, a não ser pela voz poética que estabelece contato com o leitor na recepção dos poemas. Neles, submergem o pensamento, as ideias, as impressões, o deslumbramento do eu lírico frente aos brinquedos e às brincadeiras da infância, que repetimos, pode ser a do autor. A potencialidade da manifestação do eu lírico tem, no texto poético, capacidade de recuperar, pelo menos em partes, o universo cultural no qual os poemas foram gestados e concebidos. Ouvir atentamente a voz do eu lírico também é uma maneira de perceber que o fazer poético é um modo de estar dentro da vida e de perceber que o poeta também está nesse processo, revelando-se na produção poética que entrega aos leitores. 
Quanto às diferenças que se operam, pelo menos em nível teórico, na diferenciação entre brinquedo e brincadeira, tomadas como manifestações da cultura popular, buscamos em Tizuko Morchida Kishimoto (2007), especialista nesse tema, algumas considerações. Segundo a pesquisadora, “[...] o brinquedo supõe uma relação íntima [do objeto] com a criança e uma indeterminação quanto ao seu uso, ou seja, a ausência de um sistema de regras quanto a sua utilização [diferentemente do jogo]”. (KISHIMOTO, 2007, p. 18). Já a brincadeira, “[...] é a ação que a criança desempenha ao concretizar as regras do jogo, ao mergulhar na ação lúdica. Pode-se dizer que é o lúdico em ação. Desta forma, brinquedo e brincadeira relacionam-se diretamente com a criança e não se confundem com o jogo". (KISHIMOTO, 2007, p. 21). O brinquedo e a brincadeira não se confundem com o jogo porque, entendemos, os dois primeiros têm mais relação com a infância e o terceiro é de todas as idades. Como notamos na diferenciação que Kishimoto faz entre brinquedo e brincadeira, o primeiro é basicamente o objeto que produz a ação do brincar, a brincadeira. Assim, percebemos facilmente como ambos os conceitos estão interligados.

Levantadas essas questões, seguimos com breve análise de alguns poemas que compõem a obra. Para dar forma ao trabalho, reorganizamos os poemas a partir de dois eixos: os brinquedos e as brincadeiras.

\section{Os brinquedos}

Nesta seção, escolhemos alguns poemas que, pelos seus títulos, ou pelo conteúdo que apresentam, podem, em nosso entendimento, figurar aqui. O poema de abertura e o poema que fecha a coletânea são os únicos, que, ao nosso ver, precisam ser lidos nessa ordem. Todos os demais, segundo nossa concepção, podem ser lidos aleatoriamente, o que nos permitiu organizarmos as seções de modo que favorecesse as reflexões. O poema de abertura, por coincidência, pelo título e pelo conteúdo, encaixa-se nesta seção:

\section{BRINQUEDO}

Brinquedo parado é enfeite.

Brinquedo sem dono tem sede. 
Brinquedo em loja vive à toa.

Brinquedo guardado não voa.

Brinquedo quebrado não cresce.

Brinquedo esquecido não mexe.

Brinquedo escondido é vergonha.

Brinquedo embrulhado não sonha.

Brinquedo proibido é tão triste.

Brinquedo feio não existe.

(CUNHA, 2018, p. 7).

O poema que abre o livro faz um convite ao leitor, de modo bem mais sutil que José Paulo Paes faz em Poemas para brincar, com o poema de abertura da obra que é intitulado, justamente, "Convite". Na opção de Leo Cunha pelos dísticos, em cujos versos o eu lírico revela as desvantagens de não se ter os brinquedos à mão e à vontade, reside um convite discreto para que o pequeno leitor, que lerá ou conhecerá a obra pelas mãos ou pela VOz (seria mais certo dizermos assim) do mediador, explore o universo dos brinquedos por completo, potencialmente. Mas não cabe aqui a comparação de qual dos dois autores concebeu uma abertura melhor para o seu livro. Cabe, sim, notarmos que os poemas que abrem muitas coletâneas, para a literatura de todas as idades, propõem um diálogo com todo o restante da obra, como o fizeram José Paulo Paes, Leo Cunha e Oswald de Andrade, em Pan Brasil, para citar uma coletânea para adultos, na qual o poema Escapulário funciona como uma espécie de oração, intertexto do Pai Nosso, em que o eu lírico pede a Deus inspiração para conceber aqueles quase 30 poemas modernistas.

BONECA

Ela é de pano

e dorme aqui

na minha cama.

Ela é de lata

e fala feito

maritaca. 
Ela é de plástico

e adora

se enfeitar.

É de borracha

e outra igual...

ninguém acha!

É porcelana

e sei que ela

também me ama.

(CUNHA, 2018, p. 14)

O eu lírico, nesse conjunto de cinco estrofes de três versos, apresenta ao leitor cinco bonecas diferentes. Na quarta estrofe, foi possível construir uma rima entre "borracha" e "acha”, já em outras estrofes nota-se um esforço do escritor no sentido de ajustar os sons, como é o caso da segunda estrofe, em que os sons de "lata" e "maritaca" aproximam-se, e da sexta estrofe, na qual os sons de "porcelana" e "ama" assemelham-se $e^{7}$. O poema revela a diversidade de materiais que os fabricantes utilizam na confecção ou industrialização do objeto em questão: os artesãos, que geralmente constroem as bonecas de pano (ou mesmo os familiares, como as mães e as avós), as indústrias, que fabricam bonecas a partir da lata, do plástico, da borracha e da porcelana. Consideramos muito apropriado o fato de o eu lírico não vincular a boneca ao universo feminino, deixando esse tipo de referência fora de suas indagações, bem aos moldes do que se espera contemporaneamente dos produtos culturais para a infância, sem esquecer-se de que, por muito tempo, os brinquedos e a literatura para a infância foram classificados em brinquedos e literatura para meninos e brinquedos e literatura para meninas. Quem conhece os aspectos teóricos que embasam os estudos dessa área sabe do tamanho do equívoco que é segmentar tais artefatos culturais por gênero.

\footnotetext{
${ }^{7}$ Neste trabalho levaremos em conta somente a rima chamada "soante"(ou seja, aquela em que há repetição total das vogais e consoantes), uma vez que é o tipo de rima predominante na língua portuguesa. Classificar todas as rimas dentro dos encaminhamentos teóricos disponíveis nos estudos da literatura demandaria um trabalho que não prevemos para esta escrita.
} 


\section{ANZOL}

Na ponta da linha

do horizonte,

a pipa mergulha no céu

e pesca uma nuvem.

(CUNHA, 2018, p. 34)

A imagem criada pelo eu lírico destoa propositalmente e lindamente do que se poderia esperar a partir do título. Dele, pode-se depreender uma atividade corriqueira, a pescaria, muitas vezes praticadas na companhia das crianças, com a alegria e a festividade encontradas também nas brincadeiras. Contudo, o que o leitor encontra nos quatro breves versos que compõem o poema é a utilização da imagem poética para pensar a "pescaria" sob outra perspectiva. O anzol, nesse jogo, é a pipa, que pesca uma nuvem. Essa possibilidade, construída pela linguagem poética, causa deslumbramento no leitor, que precisa jogar rapidamente (como salientamos, o poema é breve) com o devaneio poético do eu lírico. Chama atenção também a simplicidade do poema, o que demonstra que nem sempre é preciso um arranjo complexo de léxico, ritmos e rimas para se criar uma imagem bela e tocante. Em “Varetas", a imagem construída é colorida e, ao mesmo tempo, nostálgica:

\section{VARETAS}

Brincar é fazer bagunça?

Isso é só o que você pensa.

Quem já brincou de varetas sabe que a história é outra.

Pois aquela confusão colorida lá no chão

vai diminuindo a cada varetinha que é tirada.

Tudo na ponta dos dedos, coração cheio de medo, como alguém que desmonta 
não um jogo:

uma bomba.

(CUNHA, 2018, p. 17)

O conjunto de seis dísticos, dois deles rimados ("confusão" e "chão"; "cada" e "tirada"), e a manifestação do eu lírico com uma linguagem acessível e próxima do coloquial podem levar o leitor a imaginar o emaranhado de varetinhas próprio dessa brincadeira: “[...] aquela confusão / colorida lá no chão”. (CUNHA, 2018, p. 17). Esses são os versos que mais contribuem para a construção da imagem principal do poema. O eu lírico imprime sentimentos e emoções, principalmente no quinto e no sexto versos: o "coração cheio de medo" e a comparação da dinâmica do jogo com uma bomba dão ao poema as características das quais falávamos.

\author{
TRENZINHO \\ Piuiii! Lá vem o trem, \\ tudo pronto na estação. \\ Piuiii! Chegou o trem, \\ passageiros, atenção! \\ Piuiii! Lá vai o trem, \\ cada um no seu vagão. \\ Piuiii... Cadê o apito? \\ Agora é tarde, seu moço. \\ Da cozinha vem o grito: \\ - Tá na hora do almoço! \\ (CUNHA, 2018, p. 39).
}

"Trenzinho", composto de três dísticos e um quarteto (que, mergulhando no universo lúdico do eu lírico, podemos dizer que se trata da cabine do trem e seus três vagões), apresenta uma atividade recorrente na infância de muitas crianças, a brincadeira com o trem. O curioso é que a criança não precisa ter em mãos exatamente um trenzinho para que as situações lúdicas como as retratadas no poema aconteçam. De acordo com Marina Marcondes Machado (2010, p. 35), 
[...] tudo aquilo do mundo real que for usado pela criança para fazer suas experiências e descobertas, para expressar-se e lidar com seu mundo interno e subjetivo, diante da realidade desses objetos, das coisas concretas e objetivas, pode ser considerado brinquedo. [...] Nas mãos da criança saudável, qualquer coisa pode tornar-se um brinquedo.

Importante compreender, a partir de Machado, que o trenzinho apresentado no poema pode ser, na realidade, um pedaço de madeira, de tijolo, outro carrinho, caixas, cones de linha, e mesmo nem existir materialmente. É necessário apostar na capacidade de a criança fantasiar e conceber seu mundo imaginário e os elementos que o seu mundo interior consegue externalizar. Por isso, trouxemos à nossa escrita a proposição de Machado. Seja qual for o material sob o qual incide o poder de criação dos pequenos, a realidade que ele projeta é completa, como parece completa ao eu lírico de “Trenzinho". Detalhes como a estação, a presença dos passageiros, a divisão do trem em vagões corrobora com essa ideia.

$\mathrm{Na}$ concepção do poema, o autor valeu-se de um esquema de rimas que envolve, inicialmente, os três dísticos. Neles, as rimas se correspondem em dois movimentos: no primeiro verso de cada dístico, com a repetição da expressão “trem”, e no segundo verso de cada dístico, na seguinte cadeia sonora: "estação", "atenção" e "vagão". A reiteração da expressão "Piuiiii!" no início de cada estrofe também contribui para a sonoridade do poema. Quanto ao quarteto, ele apresenta o esquema de rimas $\mathrm{ABAB}$ (conhecidas como alternadas ou cruzadas) na utilização das expressões "apito" e "grito" (primeiro e terceiro versos, respectivamente) e "moço" e "almoço" (segundo e quatro versos, respectivamente).

No campo semântico, é importante perceber que a criança que brinca nesse poema encontra-se submersa nas aventuras protagonizadas pelo trenzinho, tanto que a voz que se expressa nos versos é a da própria criança, diferentemente da maioria dos outros poemas da coletânea, que trazem um olhar do eu lírico em relação ao brinquedo e à brincadeira. $\mathrm{O}$ eu lírico que brinca nos três dísticos é interpelado no quarteto, quando faz o último "Piuiii" do poema: "Cadê o apito?", diz o seu interlocutor. Então vem a resposta do brincante informando que estão chamando na cozinha, porque é hora do almoço. Dessa cena corri- 
queira, podemos deduzir que brincar, na infância, só não é mais importante do que se alimentar. Só mesmo o momento da refeição poderia atrapalhar a imersão da criança no mundo da brincadeira. Também, pensando numa outra perspectiva, poderíamos entender o ato de brincar simbolicamente, como o alimento mais apropriado à criança, que se utiliza desta ação com o potencial de uma linguagem, a maneira que ela possui de, nos primeiros anos de vida, comunicar-se com o mundo no qual ela habita. Neste sentido, o alimento que provém das atividades lúdicas da infância torna-se infinitamente mais importante que o alimento real.

$$
\begin{aligned}
& \text { DESAFIO } \\
& \text { Bibolquê } \\
& \text { Bliboquê } \\
& \text { Biboclê } \\
& \text { Bilboquê } \\
& \text { Ufa, acertar esse troço } \\
& \text { é difícil como o quê! } \\
& \text { (CUNHA, 2018, p. 26) }
\end{aligned}
$$

O poema "Desafio", embora breve, explora criativamente a brincadeira impulsionada pelo objeto/brinquedo, conhecido como bilboquê. A genialidade do poema está no fato de o eu lírico tentar acertar a palavra - o nome do brinquedo - e isso reproduzir as tentativas de a criança (ou o próprio eu lírico) encaixar uma parte do brinquedo na outra. Essa ambiguidade, reforçada na última estrofe - já que o eu lírico pode estar se referindo às tentativas de pronunciar/escrever o nome do brinquedo ou as jogadas -, não desqualifica o poema, pelo contrário, torna-o mais lúdico, porque jogar com essas duas possibilidades e realizar as duas leituras projetadas pelo texto são atividades agradáveis e engraçadas, que potencializam a capacidade da criança de perceber diferentes movimentos de significados nos versos de Leo Cunha.

\section{FANTASIA}

Depois do carnaval, rainhas, bruxas e bichos 
se fazem de gente normal.

(CUNHA, 2018, p. 47)

O também breve poema "Fantasia" subverte a lógica dos foliões do carnaval que se fantasiam (daí vem o título) de personagens, quando o eu lírico afirma que depois dos festejos as personagens fingem-se de "gente normal". Essa inversão, já que a tendência do leitor é pensar o contrário - ou seja, durante o ano os foliões são "gente normal" e no carnaval se fantasiam de "rainhas, bruxas e bichos" -, propõe um exercício parecido com o do poema analisado anteriormente. Há novidade, descoberta e deslumbramento por parte do eu lírico e, por consequência, da parte do leitor, que se vê acometido pela criatividade que a ideia e surpresa expõem. No fechamento da seção, trazemos o poema "Livro", para fazermos algumas considerações:

LIVRO

Livro é brinquedo pra agitar

e cantiga pra ninar.

Livro é cantinho pra eu me esconder

e mar aberto pra eu mergulhar.

Livro é tesouro pra gente encontrar sozinho

e floresta pra turma se aventurar.

(CUNHA, 2018, p. 8)

É curioso perceber que o poema, quando lido pela criança, estará no suporte livro, o que nos remete a um ato metatextual, parecido com o que Gérard Genette chamou de metatextualidade, ao propor o estudo das relações transtextuais em Palimpsestos (2010). Em outra obra do autor, Introdução ao arquitexto (1986), ele afirma que a metatextualidade é “[...] a relação transtextual que une um comentário ao texto que comenta”. (GENETTE, 1986, p. 97). Nesse percurso, ele inclui a metatextualidade entre os cinco tipos possíveis de relações transtextuais, utilizando o termo "transcendência textual" para designar o procedimento que coloca um texto em relação explícita com outros textos. Nesse caso, o processo 
metatextual de construção do livro ou narrativa transforma-o em um objeto de leitura dupla, já que nele estão "ficcionalizados" tanto a matéria ficcional, quanto o comentário sobre a escritura-leitura da ficção. Rodrigo da Costa Araújo, em ensaio sobre o tema, afirma:

Ficcionalizando o processo de leitura, então, a narrativa sugere uma construção que olha para si mesma, apontando para o seu processo, refletindo criticamente sobre os mecanismos utilizados na escritura e construindo, de certa forma, um modo de como deve ser lida. [...]. A metatextualidade, nesse caso, funciona como um recurso metafórico para falar do ato de ler e da literatura em si mesma, como objeto desejado, encantador e envolvente. O prefixo "meta" remete à relação crítica e se estabelece no apelo que um texto faz à sua própria interpretação. Essa atividade crítica e discursiva inserida nos livros sugere a preocupação do artista/escritor em mostrar-se consciente de sua atividade de operação sobre a linguagem, de construtora de discursos que se misturam, se observam e se completam. (ARAUJO, 2013, p. 25)

Embora os autores buscados não aludam à metatextualidade presente no gênero lírico, podemos realizar essa inferência a partir do poema em questão. Ele exemplifica claramente o processo que Genette e Araujo descrevem. O eu lírico, nos seis versos que compõem o poema, divididos em três dísticos, reflete sobre a importância do livro e do ato de

leitura. É, de fato, um comentário que se une ao texto que comenta, bem aos moldes do que prevê Genette; um olhar do texto para si mesmo, como quer Araujo.

\section{As brincadeiras}

$\mathrm{Na}$ escolha dos poemas que analisamos nesta seção, o leitor dar-se-á conta com facilidade de que nosso critério para a escolha foi o fato de as atividades lúdicas, aqui, não fluírem do encontro entre a criança e um objeto, no caso, os brinquedos. Assim, brincadeiras tradicionais ou outras menos conhecidas são o tema dos poemas que seguem, como é o caso da amarelinha:

\section{AMARELINHA}

Solta a pedra, salta a casa numa perna. 


\section{Outra perna, volta o tempo, cata a pedra. \\ Era minha vez ou sua? Amarelinha! \\ Era nossa rua, era sua e minha. \\ Amarelinha numerada de um ao céu, quem pisar na linha fica ao léu.} (CUNHA, 2018, p. 12)

O movimento que o autor imprime nas duas primeiras estrofes oferece dinamismo a elas, na utilização dos verbos soltar, saltar, voltar e catar. Esse dinamismo é acelerado, uma vez que os verbos são conjugados na primeira pessoa do singular, no presente do indicativo, o que resultou na repetição da última sílaba: "solta", "salta", "volta" e "cata". Notamos que o eu lírico estabelece um diálogo com alguém que pode ser outro brincante ou o próprio leitor. Nessa interlocução, ele lança uma pergunta, que denota o relaxamento e a descontração causados pela brincadeira, a ponto de os brincantes confundirem-se sobre a vez de cada um jogar. A resposta parece-nos do interlocutor ou interlocutora e amplia o universo da amarelinha para o espaço da rua, como que insinuando que, ao brincar, as crianças potencializam as atividades a ponto de sentirem-se donos da rua. No fechamento, a única estrofe de quatro versos (as outras são de três) arremata as ideias do poema e brinca com o fato de quem pisar na linha ficar ao léu. É importante perceber que o poema com versos tão curtos e linguagem tão transparente dialoga com a poesia de origem folclórica (ou poesia oralizada, como muitos especialistas vêm chamando as manifestações da poesia ligadas ao folclore). Não é de se admirar, pois poesia folclórica e brincadeiras tradicionais nascem no bojo da cultura popular e Leo Cunha, conhecedor dessas questões, facilmente soube unir a vocação do poema infantil para o diálogo com essas manifestações culturais. 


\section{CIRANDA}

Passa-anel, senão a ciranda acaba.

Cabra-cega, ninguém pode olhar pra lua.

Mãe-da-rua, você vai fugir pra onde?

Pique-esconde, bem depressa, não espera.

Serra-serra, serrador, conta com a gente.

Bente-altas, cuida bem da sua casa.

Passa-anel, senão a ciranda acaba...

(CUNHA, 2018, p. 21)

"Ciranda" acumula um conjunto de brincadeiras, de modo a trazer ao leitor um apanhado do que se brincou pelas ruas e escolas Brasil afora, ou talvez ainda se brinque. Pode ser que o leitor curioso indague a um adulto "O que é o passa-anel?”, “O que é a cabra-cega?", "E o pique-esconde?". Importante notar que o autor colocou "na roda" todas essas brincadeiras, como se, de fato, juntas elas formassem uma ciranda. Essa ideia é reforçada no poema pelo fato de o eu lírico abrir e fechar o poema, que é de um única estrofe, com o mesmo verso: "Passa-anel, / senão a ciranda acaba". (CUNHA, 2018, p. 21). Assim, uma ciranda, que tem o formato circular, preserva a circularidade que a repetição dos versos oferecem.

\section{PULA-CARNIÇA}

Pula-carniça,

é a sua vez, nada de preguiça!

Pula-carniça, anda bem depressa, ou a fila enguiça!

(CUNHA, 2018, p. 30) 
"Pula-carniça" - também conhecida como pula-mula ou pula-sela - lembra, de imediato, assim como o poema anterior, os poemas da poesia folclórica, pela brevidade, pelo tom coloquial da linguagem e pela funcionalidade das rimas. Em cada estrofe, foram inseridas rimas com a palavra "carniça", resultando num esquema de rima $\mathrm{ABA} A B A$, que não encontra uma classificação correspondente nos estudos de poesia em língua portuguesa. Notamos, porém, que elas se assemelham um pouco com as rimas interpoladas ou intercaladas, que apresentam o esquema ABBA. No campo semântico, o eu lírico dá ordens para que o fluxo da brincadeira não diminua, já que a pula-carniça exige empenho e agilidade para que os participantes não acabem amontoados, o que é um momento divertido da brincadeira.

\author{
VACA AMARELA \\ Quem falar primeiro \\ come mosca, \\ morde a língua, \\ engole sapo, \\ cospe marimbondo, \\ vai lamber sabão. \\ Eu é que não falo não! \\ (CUNHA, 2018, p. 32)
}

O poema parte da conhecida brincadeira chamada de vaca amarela e insere várias possibilidades de castigos para quem quebrar a regra da brincadeira, que não é falar. $\mathrm{O}$ eu lírico, após apresentar tais possibilidades, afirma: “Eu é que não falo não!” (CUNHA, 2018, p. 32), momento em que, a nosso ver, ele estaria quebrando a brincadeira, trazendo leveza e humor ao poema. Não há preocupação com rimas, embora a utilização de recursos sonoros fique evidente nos versos que iniciam com verbo, todos eles no imperativo e quase todos terminados em "e" ("come”, "morde", "engole”). E, para finalizar a seção, o poema que encerra a obra e dá título à coletânea:

\title{
SÓ DE BRINCADEIRA
}

Brincar de poesia

não tem fim. 
Ela já saltou da folha

pro seu olho,

ela já está de molho

em sua cuca.

Parece coisa maluca, mas você não tem escolha.

A poesia chacoalha

o corpo

e também

a mente.

A poesia, minha gente,

ela é assim

e fim.

(CUNHA, 2018, p. 55)

Mais uma coincidência: o poema que fecha a coletânea faz parte do segundo grupo de poemas, segundo nossa divisão, permitindo que ele seja analisado no fechamento do trabalho. Ele evoca um tipo de brincadeira que nos é muito caro e - cremos - ao autor também: a brincadeira com a poesia. Inicialmente ela tematiza a "infinitude" da poesia. Pelo que deduzimos da segunda estrofe, o eu lírico refere-se à poesia escrita, ao poema, que, segundo ele, salta da folha, para o olho, para a cuca. Para ele, a poesia mexe com o corpo das pessoas e também com o universo interior. Uma afirmativa fecha o poema, de modo a confirmar o que foi levantado e a encerrar o poema, em definitivo, utilizando-se da expressão "e fim".

O poema, por constituir parte de uma obra literária impressa do gênero lírico, participa do universo que assinalamos anteriormente para uma melhor compreensão do poema "Livro", a partir de Genette e Araujo. Aqui temos as características das poesias/poemas quando da sua recepção ou leitura. É uma reflexão sobre o próprio ato que a obra toda mobiliza: o de ler poesia. Dessa maneira, o poema participa de um largo campo de especulação teórico, que tem mobilizado especialistas, pesquisadores e autores de literatura. 


\section{Considerações finais}

O processo de representação na literatura denota uma atitude perante o mundo e as pessoas que está longe de ser simplista ou corriqueira. Margarida Medeiros (2000, p. 36) dá-nos a dimensão desse processo na literatura e nas artes em geral:

A representação do Outro ou de si surge pois como manifestação de uma presença no mundo, como ponto de vista sobre esse mundo, mas também como forma de potencialmente o recriar ou restaurar. Representar é sempre revolucionar. É sempre uma forma de protesto contra o desvanecimento do ser no tempo.

Remetendo a essência desse fragmento ao que encontramos em Só de brincadeira, podemos dizer que Leo Cunha protesta valentemente contra o apagamento de elementos tão importantes da cultura infantil na terra: os brinquedos e as brincadeiras. Seus poemas recriam e restauram um tempo que, muitas vezes, encontra-se esquecido, escondido e até apagado. Trata-se, nesse sentido, de revolucionar (para utilizar uma palavra de Medeiros), de propor uma revolução, na qual o poeta combate com a palavra em estado poético e com sua sensibilidade de artista.

Para não deixarmos o trabalho repetitivo, optamos por tratar pontualmente aqui de uma questão chave levantada na Introdução, que é observação, nos poemas, do modo que eles promovem a representação da infância na obra acolhida para o estudo. Essa representação dá-se à medida que o eu lírico lança mão de elementos relacionados aos brinquedos e brincadeiras, tais como o modo de brincar com os objetos, a maneira de manuseá-los, os materiais dos quais são fabricados, a emoção e o sentimento que eles despertam nas crianças, entre outros. Também é importante percebermos, nessa tentativa de representação, que os poemas que escolhemos para a seção "Os brinquedos" demonstram justamente a transmutação do brinquedo em brincadeira com facilidade, pois o objeto ou o suporte dão vazão à brincadeira, à medida que o objeto, o brinquedo, convida a criança para que a atividade lúdica aconteça. A facilidade sobre a qual nos referimos demonstra, na lírica infantil de Leo Cunha, a naturalidade de com que a criança passa de um "estágio" a outro. Nesse sentido, a representação da infância também se efetiva. 
A representação da infância, ilustrada nos brinquedos e nas brincadeiras na poética exposta em Só de brincadeira, está na simetria entre a dicção do eu lírico e as recordações que carrega de tais elementos. Essas recordações cumprem a função de tentar reaver algum aspecto do passado que se tornou importante e que merece reabitar as sensações e emoções do poeta. É nesse sentido que poetas como Leo Cunha lançam-se a empreitadas como a proposta na obra aqui comentada, para cumprirem uma necessidade particular de precisar expressar-se no mundo e porque sabem que possibilitar aos outros a experiência estética é necessário, é urgente.

\title{
CHILDHOOD REPRESENTATION IN LEO CUNHA'S POEMS FROM THE BOOK: SÓ DE BRINCADEIRA
}

\begin{abstract}
Children's reception poetry reveals a universe of feelings and perceptions of the author and they are connected to the way of representing elements related to childhood. Furthermore, these elements can be subjective or of a confessional nature, they can also be linked to children's ritual and the world projected by this kid from the actions, such as toys and plays. Leo Cunha's project, which created the book Só de brincadeira is responsible for the exploitation of these themes, more specifically, poems for childhood and its exploration (Positivo, 2018). So, these article separates the poems into two categories, poems related to toys and poems related to plays and presents analyses that seek to understand the author's way of representing childhood, taking as a starting point the poetic use of the object (the toy) or the game/activity (the play). Moreover, its analyses observe the poetic construction of Leo Cunha, taking into consideration the resources of the lyrical genre that the author mobilizes in the poems. Thus, it was possible to conclude that the poem often focuses on a toy and puts the object in a playful activity, which reveals that the play emerges from it. Therefore, Leo Cunha as an observer and creator takes advantage of this process as a poetic resource. Finally, it is easy to note Leo's latent talent in his writing, handling with poetic language and its intricacies.
\end{abstract}

KEYWORDS: Childhood poetry; Toys; Plays.

\section{REFERÊNCIAS}

ANDRADE, Oswald de. Pau Brasil. Au Sans Pareil: Paris, 1925 [2003]. Ed. fac-sim.

AYALA, Maria Ignez Novais. Aprendendo a aprender a cultura popular. In: PINHEIRO, Helder (Org.). Pesquisa em literatura. Campina Grande: Bagagem, 2003. p. 83-119.

ARAUJO, Rodrigo da Costa. Artifícios de mise en abyme: a leitura em ilustrações de livros infantis. In.: GRAZIOLI, Fabiano Tadeu; COENGA, Rosemar Eurico (Orgs.). Literatura infantojuvenil e leitura: questões, reflexões e experiências. Erechim: Habilis Press, 2013. p. 25-38. 
MACHADO, Marina Marcondes. O brinquedo-sucata e a criança: a importância do brincar, atividades e materiais. 7. ed. São Paulo: Loyola, 2010.

MEDEIROS, Margarida. Fotografia e narcisismo: o autorretrato contemporâneo. Lisboa: Assírio \& Alvim, 2000.

FREIRE. Adilce Manuela Moreno. A representação do ilhéu em Manoel Lopes. 2010. 65 f. Trabalho de Conclusão de Curso (Licenciatura em Estudos Cabo-Verdianos e Português), Universidade de Cabo Verde, Lisboa, 2010.

GENETTE, Gérard. Introdução ao arquitexto. Tradução de Cabral Martins. Lisboa: Vega, 1986.

Palimpsestos: a literatura de segunda mão. Extratos traduzidos por Cibele Braga, Erika Viviane Costa Vieira, Luciene Guimarães, Maria Antônia Ramos Coutinho, Mariana Mendes Arruda, Miriam Vieira. Belo Horizonte: Viva Voz, 2010.

GUERREIRO, Emanuel. O conceito de representação: literatura, religião e cinema. Revista Vértice, Lisboa, n. 150, jan.-fev. 2010, p. 42-52.

KISHIMOTO, Tizuko Morchida. O jogo e a Educação Infantil. In.: KISHIMOTO, Tizuko Morchida. Jogo, brinquedo, brincadeira e educação. 10. ed. São Paulo: Cortez, 2007. p. 13-43.

PAES, José Paulo. Poemas para brincar. Ilustrações de Luiz Maia. 17. ed. São Paulo: Ática, 2011.

Recebido em: 27/01/2020.

Aprovado em: 05/03/2020. 